\title{
Artificial neural network based tool wear estimation on dry hard turning processes of AISI4140 steel using coated carbide tool
}

\author{
D. RAJEEV ${ }^{1}$, D. DINAKARAN ${ }^{2}$, and S.C.E. SINGH ${ }^{3 *}$ \\ ${ }^{1}$ Department of Mechanical Engineering, Mar Ephraem College of Engineering and Technology, \\ Marthandam, Kanyakumari, Tamilnadu 629171, India \\ ${ }^{2}$ Centre for Automation and Robotics, Hindustan University, Chennai, Tamilnadu 603103, India \\ ${ }^{3}$ Department of Mechanical Engineering, Mepco Schlenk Engineering College, Sivakasi, Tamilnadu 626005, India
}

\begin{abstract}
Nowadays, finishing operation in hardened steel parts which have wide industrial applications is done by hard turning. Cubic boron nitride (CBN) inserts, which are expensive, are used for hard turning. The cheaper coated carbide tool is seen as a substitute for CBN inserts in the hardness range (45-55 HRC). However, tool wear in a coated carbide tool during hard turning is a significant factor that influences the tolerance of machined surface. An online tool wear estimation system is essential for maintaining the surface quality and minimizing the manufacturing cost. In this investigation, the cutting tool wear estimation using artificial neural network (ANN) is proposed. AISI4140 steel hardened to 47 $\mathrm{HRC}$ is used as a work piece and a coated carbide tool is the cutting tool. Experimentation is based on full factorial design (FFD) as per design of experiments. The variations in cutting forces and vibrations are measured during the experimentation. Based on the process parameters and measured parameters an ANN-based tool wear estimator is developed. The wear outputs from the ANN model are then tested. It was observed that as the model using ANN provided quite satisfactory results, and that it can be used for online tool wear estimation.
\end{abstract}

Key words: hard turning, coated carbide, cutting force, vibration, ANN.

\section{Introduction}

In the recent past, hard turning has been getting wide industrial acceptance over traditional grinding for the finish turning of hardened steels. Hard turning has some distinct advantages, like higher material removal rate, the same machine for soft and hard turning, less work cycle time and absence of hazardous cutting fluids [1-4]. Coated carbide tool is seen as a substitute for the expensive cubic boron nitride $(\mathrm{CBN})$ inserts which are widely used for hard turning. But tool wear in carbide inserts is higher, leading to machine downtime. It is reported that the tool wear constitutes about $20 \%$ of the total downtime, leading to a drastic increase in production costs $[5,6]$. To prevent such critical situation, the status of tool wear during machining should be known. Monitoring the status of the tool is referred to as tool condition monitoring (TCM). Many authors have shown interest in TCM [7-13]. TCM can be done using direct, as well as indirect methods. Indirect methods are popular because they can be implemented online.

Vibration, current, cutting force, power, torque, and acoustic emission acquired are the widely-used indirect methods which use sensor signals to correlate wear in machining processes. Cutting force is considered to be one of the most important parameters for predicting tool wear [14]. In worn tools, owing to the increased friction, both static and dynamic components of the three orthogonal cutting forces increase. For sensing the

\footnotetext{
*e-mail: edbertefren0420@gmail.com
}

Manuscript submitted 2016-10-05, revised 2017-01-19, 2017-02-15, 2017-02-16 and 2017-02-17, initially accepted for publication 2017-02-17, published in August 2017. cutting forces, tool dynamometers are widely used. Another prominent feature used in TCM is the vibration signal. The amplitude of the vibration signal in the dynamic frequency band of the tool holder's natural frequency along the $\mathrm{z}$ direction is more profound to wear, and it can be considered a feature for TCM [15-17].

Since tool wear is a complex phenomenon, the signal information from a single sensor is inadequate to predict the wear accurately. Hence, it is advisable to employ multiple sensors. The highlight of the multi-sensor system is the abundance of information available, which can be used for decision making. Many researchers have used a combination of force and vibration signals, as well as acoustic emission signals, to monitor tool wear and roughness [18-20].

The estimation of tool wear from the sensor signals is performed by developing a mathematical model from the experimental data, referred to as the regression equation. Since the relationship between features from sensors and tool wear are nonlinear, the regression equation may not hold well. The artificial neural networks (ANN) using a mapping technique between the input and output are extensively employed [21-23] whenever the relation is nonlinear. The selection of input parameters, hidden layer, and inner error depend upon the cutting process in ANN.

The main research factor in hard turning is the estimation wear in coated carbide cutting tool which can be used as a replacement for expensive CBN tools. Even though many investigations have been carried out on wear estimation and TCM, the research work in TCM considering multilayer coated carbide inserts on hard turning, using multiple sensors which could 


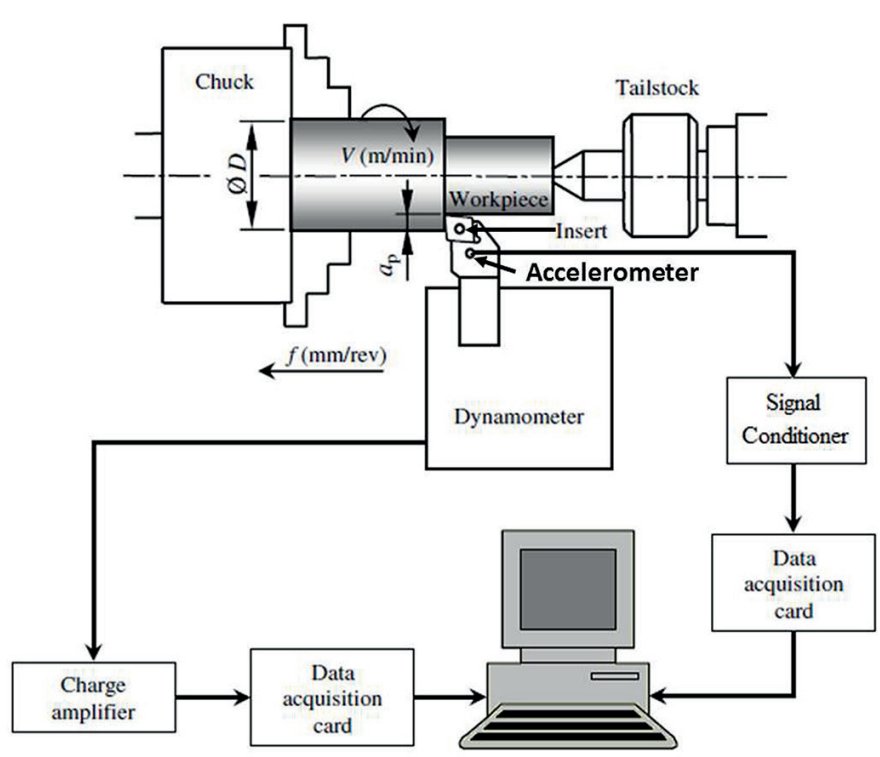

Fig. 1. Experimental procedure

sense the occurrences in machining, are very limited. Thus, the present work deals with the estimation of tool wear in coated carbide tools during hard turning of AISI 4140 steel in dry environment. An ANN-based tool wear estimator is developed based on the signals from a dynamometer, tri-axial accelerometer, cutting speed, feed, depth of cut, and machining length.

Nomenclature

$\begin{aligned} a_{\mathrm{p}} & \text { depth of cut }(\mathrm{mm}) \\ \mathrm{f} & \text { feed rate }(\mathrm{mm} / \mathrm{rev}) \\ \mathrm{F}_{\mathrm{a}} & \text { feed force }(\mathrm{N}) \\ \mathrm{F}_{\mathrm{r}} & \text { radial force }(\mathrm{N}) \\ \mathrm{F}_{\mathrm{t}} & \text { tangential force }(\mathrm{N}) \\ \text { HRC } & \text { Rockwell hardness } \\ \mathrm{V}_{\mathrm{c}} & \text { cutting speed }(\mathrm{m} / \mathrm{min}) \\ \mathrm{V}_{\mathrm{b}} & \text { tool flank wear }(\mathrm{mm}) \\ \mathrm{L} & \text { machining length }(\mathrm{mm}) \\ \mathrm{MSE} & \text { mean square error } \\ \mathrm{A}_{\mathrm{z}} & \text { power spectral density }\left(\mathrm{g}^{2} / \mathrm{Hz}\right)\end{aligned}$

\section{Experimental details}

2.1. Cutting tool, equipment, and workpiece material. The experiments have been conducted using industrial type Kirloskar lathe with $2.2 \mathrm{KW}$ spindle power in dry conditions. The work piece material is heat treated AISI4140 alloy steel. The hardness is $47 \pm 1 \mathrm{HRC}$. The dimensions of the cylinder-shaped bar used for experimentation are $80 \mathrm{~mm}$ diameter and $250 \mathrm{~mm}$ length. Prior to the machining tests, the work material was centered and cleaned by getting rid of the layer of rust from the outside surface. The cutting tool used is CVD coated $\mathrm{Ti}(\mathrm{C}, \mathrm{N})+\mathrm{Al}_{2} \mathrm{O}_{3}$

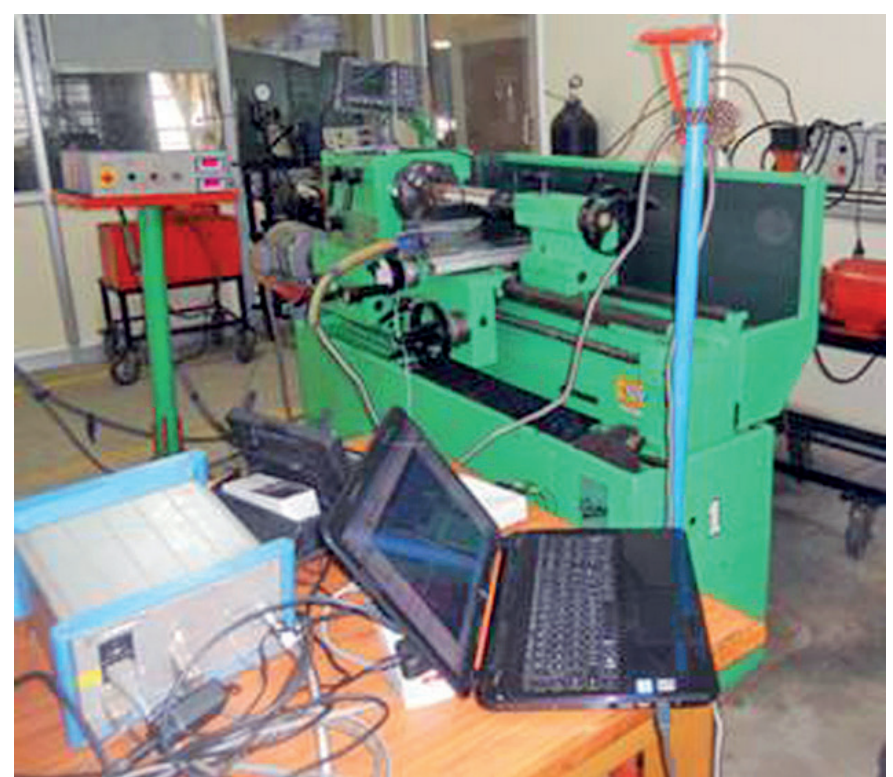

Fig. 2. Experimental setup

durotomic carbide tool, designated as TH1500 grade (manufactured by SECO). ISO designation of the cutting insert is CNMG120408 with nose radius equal $0.8 \mathrm{~mm}$. The tool holder used for the present investigation is PCLNR 2525 M12 type with the following cutting specifications: back rack angle equal $-6^{\circ}$, negative cutting edge inclination angle equal $-6^{\circ}$, major cutting edge angle equal $95^{\circ}$.

The experimental details are depicted in Figs. 1, 2.

2.2. Measurement of cutting force. By making use of a piezoelectric force dynamometer (Kistler type 9257B) the cutting forces acting on the cutting tool are sensed. Prior to the cutting experiments, calibration of the dynamo- meter is performed by applying known weights. The mean force components along the $\mathrm{x}, \mathrm{y}$, and $\mathrm{z}$-direction are measured. $\mathrm{F}_{\mathrm{y}}$ is the dominant force in hard turning, as reported in [6]. A model plot of the mean force measured along the radial direction is shown in Fig. 3. Windows-based Dynaware software is used for signal acquisi-

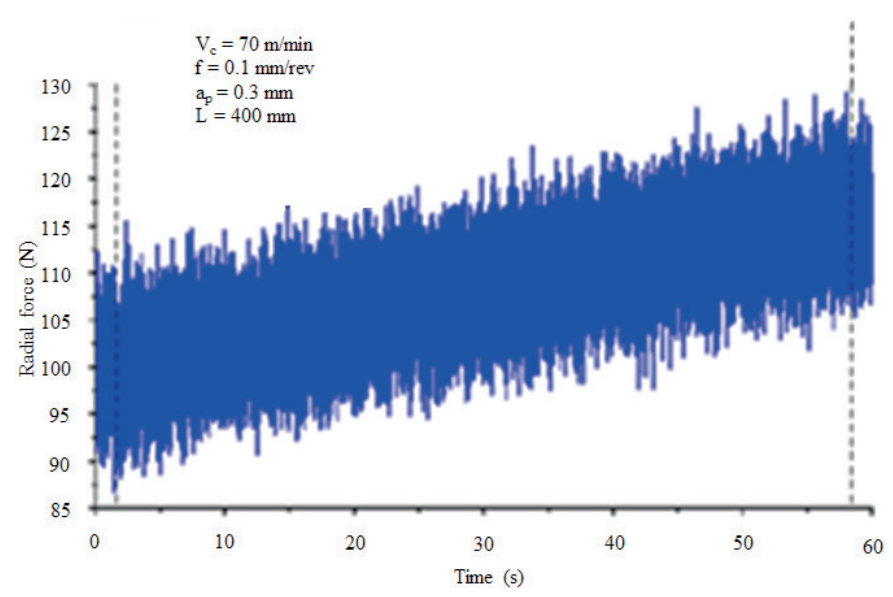

Fig. 3. Radial force plot 
tion. The mean force values collected during the experimentation is used as one of the inputs for the ANN-based tool wear estimation system.

2.3. Measurement of vibration signals. Vibration is one of the prominent signals considered for tool wear monitoring. Here, measurement of vibration is performed by means of a triaxial accelerometer made by Kistler (8766A). The amplitude of vibration signals in dynamic frequency band close to the natural frequency of tool holder is highly sensitive to tool wear $[17,18]$. The tool holder's natural frequency used for the experimentation was found to be around $4.9 \mathrm{kHz}$. Consistent peak was observed for all the experiments in the particular dynamic frequency range of $4.5-5.5 \mathrm{kHz}$. The overall amplitude in the dynamic frequency band of the vibration signal is calculated using the relation given below:

$$
\mathrm{G}_{1-2}=\sqrt{\int_{\mathrm{f}_{1}}^{\mathrm{f}_{2}} \mathrm{~S}(\mathrm{f}) \mathrm{df}}
$$

where:

$\mathrm{G}_{1-2}$ - overall amplitude in the frequency band

$\mathrm{f}_{1}-$ lower limit of frequency in $\mathrm{Hz}$.

$\mathrm{f}_{2}-$ lower limit of frequency in $\mathrm{Hz}$.

$\mathrm{S}(\mathrm{f})$ - power spectral density (PSD) function in $\mathrm{g}^{2} / \mathrm{Hz}$.

The vibration signals which are captured using an accelerometer are analysed using the Dewesoft software. The amplitude data collected during various cutting conditions are used as input values for ANN system training and testing. The power spectral density plot for vibration signal is depicted in Fig. 4.

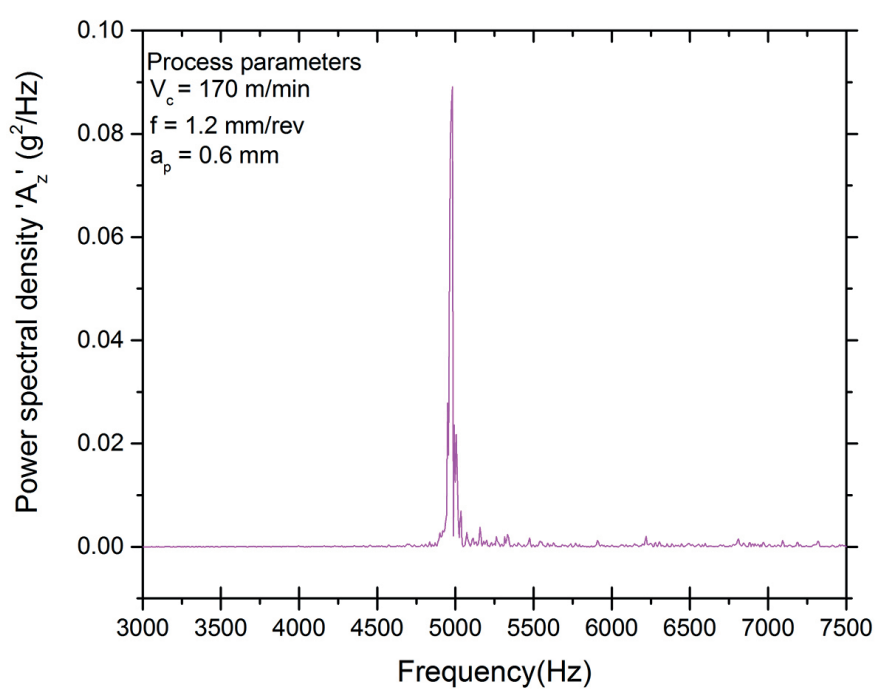

Fig. 4. Power spectral density plot

2.4. Measurement of tool flank wear. To measure tool flank wear, the insert is detached fom the tool holder after machining. Optical microscope is used for measuring the tool flank wear. The tool flank wear image acquisition for a particular cutting condition $\left(\mathrm{V}_{\mathrm{c}}=170 \mathrm{~m} / \mathrm{min}, \mathrm{f}=0.1 \mathrm{~mm} / \mathrm{rev}, \mathrm{a}_{\mathrm{p}}=0.3 \mathrm{~mm}\right.$, and $\mathrm{L}=600 \mathrm{~mm}$ ) is shown in Fig. 5.

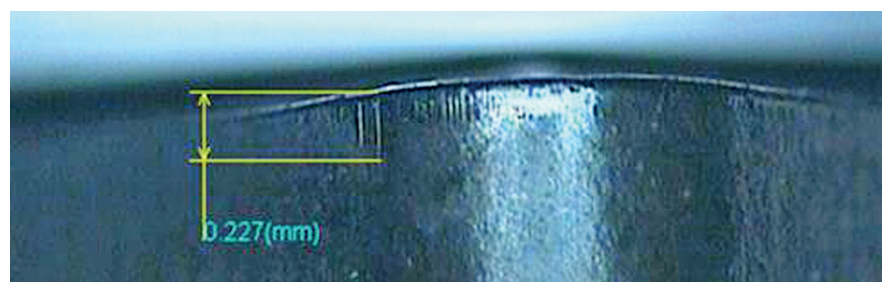

Fig. 5. Optical microscope image of tool flank wear

\section{Experimental designs}

For systematic carrying out of the experiments, all the cutting conditions are framed as per design of experiments (DOE). The levels of process parameters considered are given in Table 1. A total of 81 experimental conditions are formulated as per the full factorial design (FFD). For formulating the ANN network, the data from experimentation are used. The recommended range specified by SECO is $\left(\mathrm{f}=0.08-0.3 \mathrm{~mm} / \mathrm{rev}\right.$ and $\mathrm{a}_{\mathrm{p}}=0.2-3 \mathrm{~mm}$ )

Table 1

Factors and their levels

\begin{tabular}{|c|c|c|c|c|}
\hline Level & $\mathrm{V}_{\mathrm{c}}(\mathrm{m} / \mathrm{min})$ & $\mathrm{f}(\mathrm{mm} / \mathrm{rev})$ & $\mathrm{a}_{\mathrm{p}}(\mathrm{mm})$ & $\mathrm{L}(\mathrm{mm})$ \\
\hline 1 & 70 & 0.08 & 0.30 & 200 \\
\hline 2 & 120 & 0.10 & 0.45 & 400 \\
\hline 3 & 170 & 0.12 & 0.6 & 600 \\
\hline
\end{tabular}

\section{Feature selection}

4.1. Influence of process parameters. To find the influence of cutting speed (v), feed rate (f), depth of cut $\left(a_{p}\right)$ and length (L) on tool wear, the analysis of variance is carried out. The ANOVA table is depicted in Table 2. Table 2 of ANOVA shows the de-

Table 2

ANOVA for tool wear

\begin{tabular}{|l|c|c|c|c|c|c|}
\hline Source & DF & SS & MS & F & P & Remarks \\
\hline $\mathrm{V}_{\mathrm{c}}$ & 2 & 0.0569 & 0.028476 & 47.47 & 0 & significant \\
\hline $\mathrm{f}$ & 2 & 0.0154 & 0.007703 & 12.84 & 0 & significant \\
\hline $\mathrm{a}_{\mathrm{p}}$ & 2 & 0.0377 & 0.018898 & 31.51 & 0 & significant \\
\hline $\mathrm{L}$ & 2 & 0.1901 & 0.095052 & 158.46 & 0 & significant \\
\hline $\mathrm{Vc} * \mathrm{f}$ & 4 & 0.0043 & 0.001089 & 1.82 & 0.141 & insignificant \\
\hline $\mathrm{Vc}$ ap & 4 & 0.0018 & 0.000474 & 0.79 & 0.537 & insignificant \\
\hline $\mathrm{Vc} \mathrm{L}^{*}$ & 4 & 0.0022 & 0.000569 & 0.95 & 0.444 & insignificant \\
\hline $\mathrm{f}^{*} \mathrm{ap}$ & 4 & 0.0032 & 0.000806 & 1.34 & 0.267 & insignificant \\
\hline $\mathrm{f}^{*} \mathrm{~L}$ & 4 & 0.0012 & 0.000308 & 0.51 & 0.726 & insignificant \\
\hline ap*L & 4 & 0.0020 & 0.000506 & 0.84 & 0.504 & insignificant \\
\hline Error & 48 & 0.0287 & 0.0006 & - & - & - \\
\hline Total & 80 & 0.3440 & - & - & - & - \\
\hline
\end{tabular}


grees of freedom (DF), sum of squares (SS), mean squares (MS), F-values $(\mathrm{F})$, and probability $(\mathrm{P})$. A low P-value $(\leq 0.05)$ indicates statistical significance for the source on the corresponding response (i.e. $\alpha=0.05$ or $95 \%$ confidence level), indicating that the obtained models are considered to be statistically significant, which is desirable, as it demonstrates that the terms in the model have a significant effect on the response. It is evident from Table 2 that the length and velocity are the significant parameters affecting tool wear, followed by depth of cut and feed.

4.2. Influence of cutting force on flank wear. All the three components of force $\left(\mathrm{F}_{\mathrm{a}}, \mathrm{F}_{\mathrm{r}}\right.$, and $\left.\mathrm{F}_{\mathrm{t}}\right)$ are measured and the variations of force with wear are investigated, as in Fig. 6. All the turning forces components show an increasing trend with wear.

The reason for this trend is that when wear increases, the area of contact also increases. This leads to more friction between the work piece and tool, which, in turn, increases the static and dynamic components of force. All the conditions reflect higher value for the thrust component of force along the radial direction $\left(\mathrm{F}_{\mathrm{r}}\right)$ followed by tangential component $\left(\mathrm{F}_{\mathrm{t}}\right)$ and feed thrust component $\left(\mathrm{F}_{\mathrm{a}}\right)$. The similar was experienced by previous researchers $[1,3]$. The reason for the high value of thrust component is attributed to the spring back effect of hardened material.

4.3. Influence of vibration on wear. Power spectral density (PSD) amplitude of the vibration signal increases with wear in the $\mathrm{z}$-direction. The amplitude along the $\mathrm{z}$-direction is higher compared to $\mathrm{x}$ and $\mathrm{y}$ directions. A similar trend was observed by Dimla et.al [16]. However, the overall amplitude is low. This is because the rigid clamping of the tool holder in the tool post and the tool holder acts like a cantilever beam. Fig. 7 shows the variation of power spectral density over tool wear for cutting condition $\left(\mathrm{V}_{\mathrm{c}}=170 \mathrm{~m} / \mathrm{min}, \mathrm{f}=1.2 \mathrm{~mm} / \mathrm{rev}\right.$, and $\left.\mathrm{a}_{\mathrm{p}}=0.6 \mathrm{~mm}\right)$. From the power spectrum it can be seen that the average power received by the transducer increases with wear. It is because the wear results in increased friction, which in turn increases the

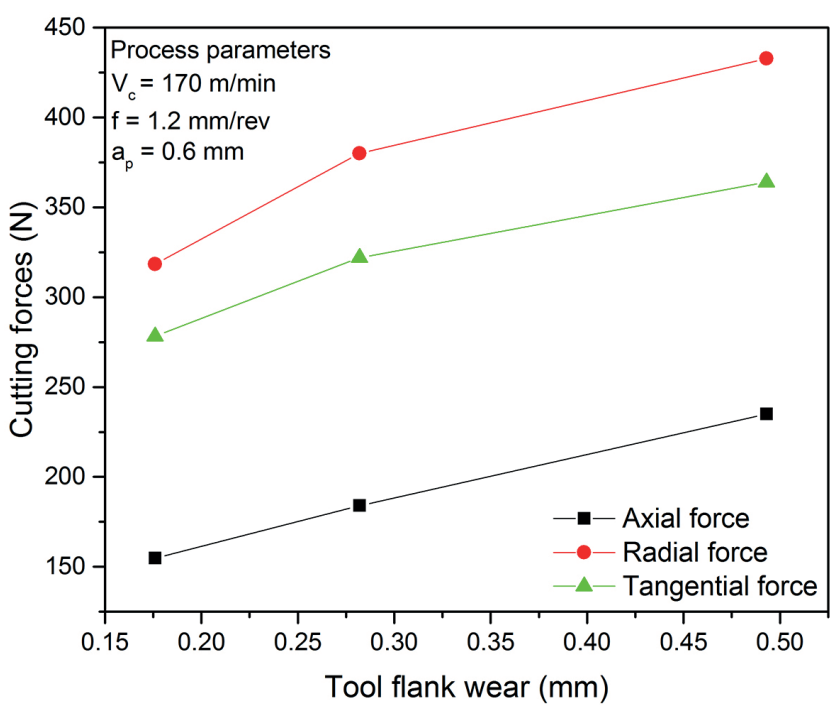

Fig. 6. Variation of cutting force with wear

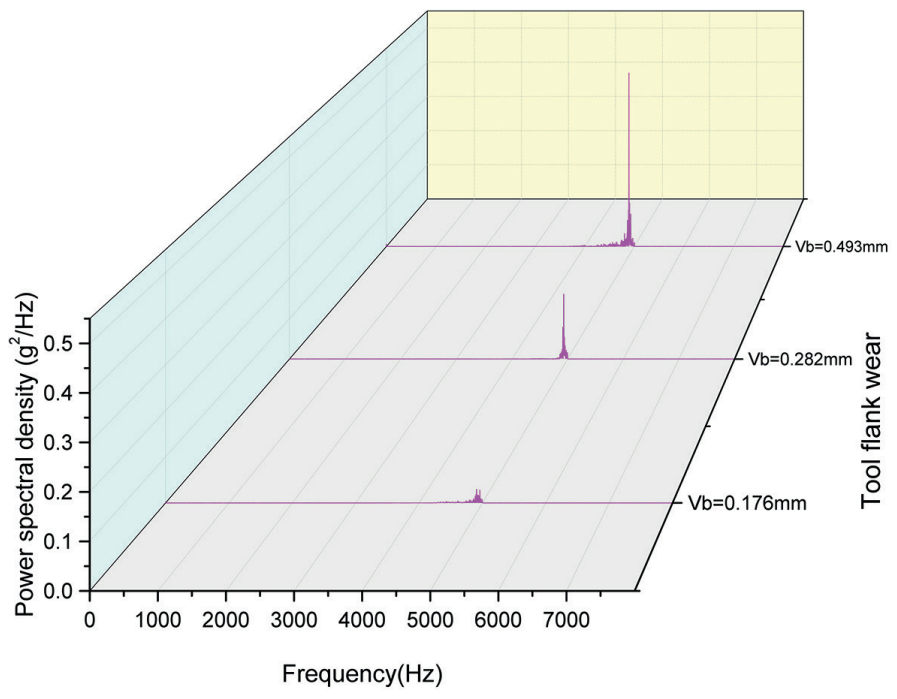

Fig. 7. Variation of power spectral density $\left(\mathrm{A}_{\mathrm{Z}}\right)$ with wear

vibration. Based on the ANOVA results and the cutting force and acceleration analysis, the following features are selected as inputs for ANN:

- Cutting speed $\left(\mathrm{V}_{\mathrm{c}}\right)$,

- Feed (f),

- Depth of cut $\left(a_{p}\right)$,

- The mean value of forces in $\mathrm{x}, \mathrm{y}$, and $\mathrm{z}$-direction $\left(\mathrm{F}_{\mathrm{a}}, \mathrm{F}_{\mathrm{r}}\right.$, and Ft),

- Power spectral density of vibration $\left(\mathrm{A}_{\mathrm{z}}\right)$ in the frequency range of $4.5-5.5 \mathrm{kHz}$

- Machining length (L)

\section{The proposed ANN architecture}

ANN is a modelling tool widely used when the relationships between the input and output are highly nonlinear in nature. In $\mathrm{ANN}$, the relation between the input and output is created by means of a simulated network consisting of interconnected neurons. The commonly used network is feed-forward neural network topology, which consists of three layers, as in Fig. 8. The ANN uses a mapping technique through which the network output is continuously updated, based on the minimum value of mean square error (MSE). This process is called training. The training process is shown in the flowchart (Fig. 9).

The algorithm widely used for training is the Levenberg-Marquardt (LM) back propagation algorithm. Mean square error (MSE) is given by:

$$
\operatorname{MSE}=\frac{1}{n} \times \sum_{j=1}^{n}\left(E_{j}\right)^{2}=\frac{1}{n} \times \sum_{i=1}^{n}(\theta j-\theta a)^{2}
$$

where:

$\mathrm{n}$ - number of epochs

$E_{j}-$ error value between the target output and network output.

$\theta_{\mathrm{j}}-$ neural network output

$\theta_{\mathrm{a}}-$ target. 


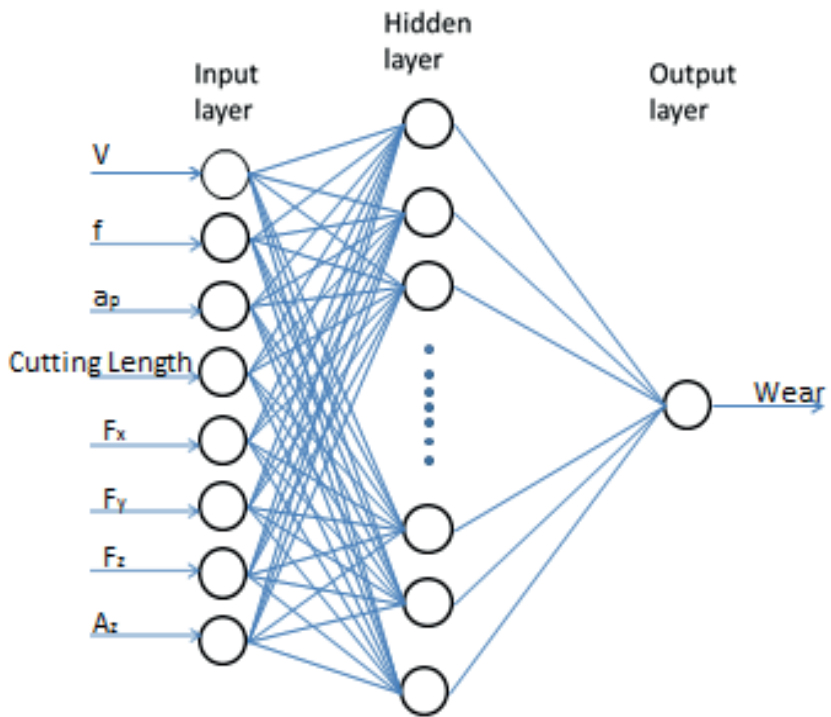

Fig. 8. ANN estimator for tool wear

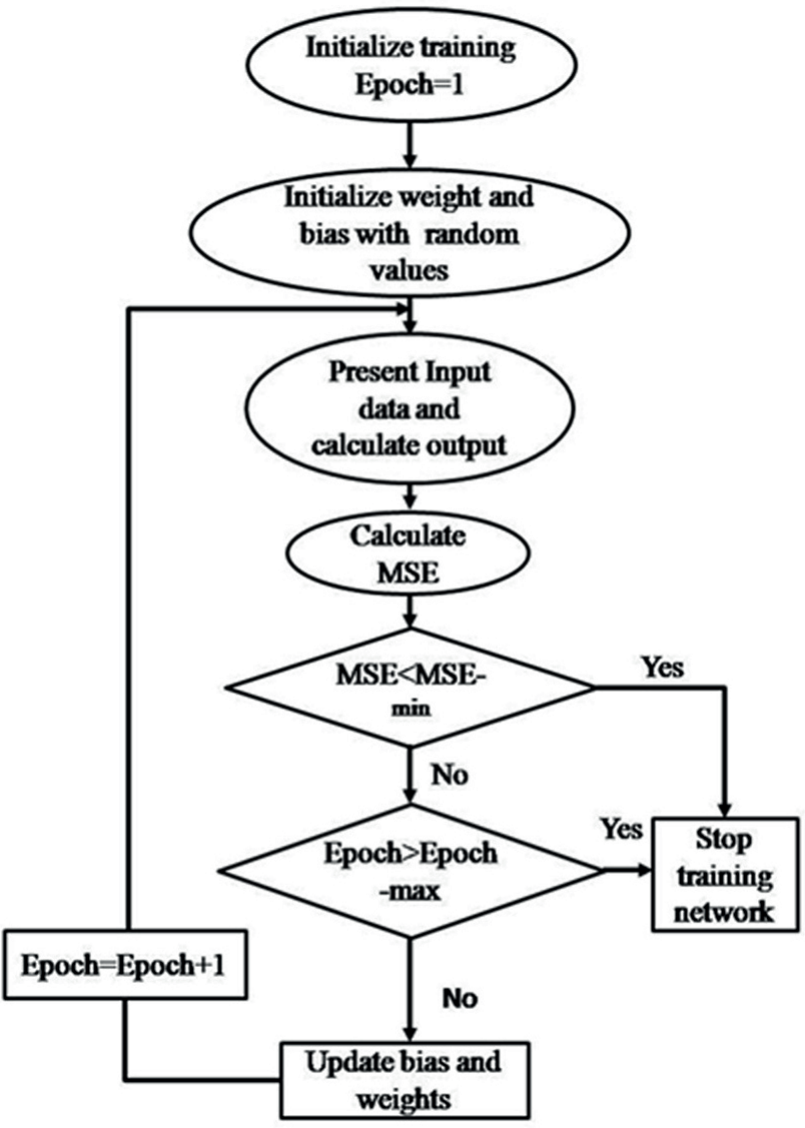

Fig. 9. The ANN training process

In this study, tool wear is predicted based on the neural network, as shown in Fig. 8. Based on the experimentation carried out, the selected features are taken as input and the tool wear is considered as output. Of the 81 cutting conditions, 57 data points (cutting conditions) are used for training, 12 cutting

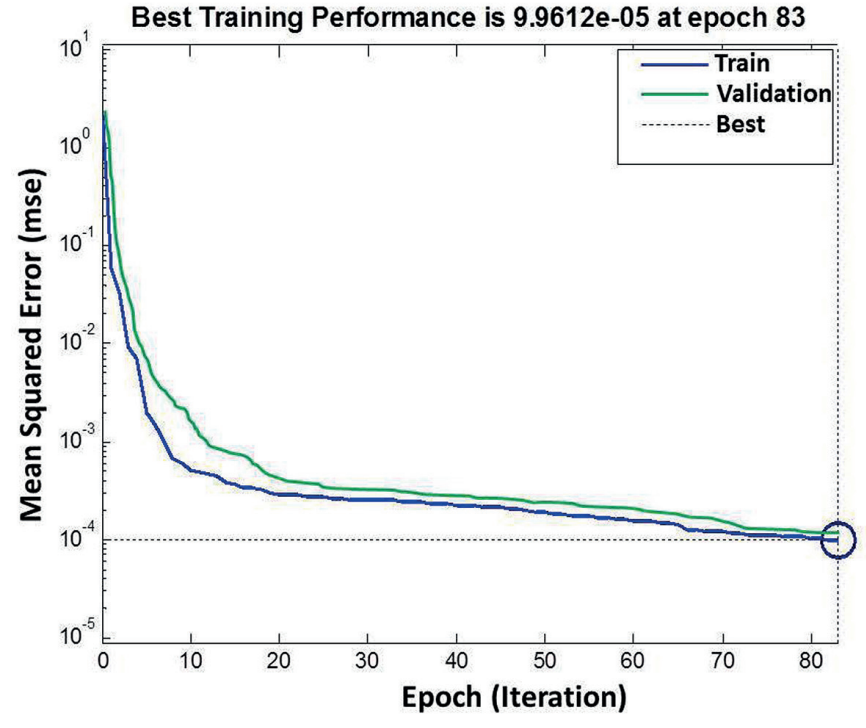

Fig.10 The Mean Square Error Plot

conditions are allotted for validation, and another 12 data points (cutting conditions) for testing. After training the data using LM back propagation [21-23] algorithm, based upon the minimum value of MSE, the optimum network is arrived at. The different trials carried out and the MSE values are shown in Table 3. In the present case, the $8-10-1$ network is the optimum network. The MSE plot for the training data and validation data is shown in Fig. 10. The network is cross-validated for the testing data.

Table 3

Selection of optimal network

\begin{tabular}{|c|c|c|c|c|}
\hline $\begin{array}{c}\text { Sl. } \\
\text { No }\end{array}$ & Structure & $\begin{array}{c}\text { Square root of } \\
\text { MSE-training } \\
(\mu \mathrm{m})\end{array}$ & $\begin{array}{c}\text { Square root of } \\
\text { MSE-validation } \\
(\mu \mathrm{m})\end{array}$ & $\begin{array}{c}\text { Square root of } \\
\text { MSE-testing } \\
(\mu \mathrm{m})\end{array}$ \\
\hline 1 & $8-5-1$ & 24.62 & 25.40 & 25.01 \\
\hline 2 & $8-6-1$ & 29.52 & 25.90 & 30.53 \\
\hline 3 & $8-7-1$ & 19.16 & 18.05 & 16.84 \\
\hline 4 & $8-8-1$ & 24.08 & 25.99 & 24.98 \\
\hline 5 & $8-9-1$ & 18.16 & 21.58 & 20.06 \\
\hline 6 & $\mathbf{8}-\mathbf{1 0}-\mathbf{1}^{*}$ & 9.98 & 16.96 & 11.12 \\
\hline 7 & $8-11-1$ & 22.65 & 26.51 & 28.70 \\
\hline 8 & $8-12-1$ & 23.02 & 18.32 & 17.14 \\
\hline
\end{tabular}

$8-10-1^{*}$ - the selected network

\section{Results and discussion}

6.1. Regression plots. Mean squared error (MSE) is a performance metric adopted to determine the network performance, while regression $(\mathrm{R})$ is used to calculate the correlation between measured and predicted values. $\mathrm{R}=1$ indicates closed relationship while $\mathrm{R}=0$ is a random relationship. A regression plot of the estimated values and measured values of tool wear for the 


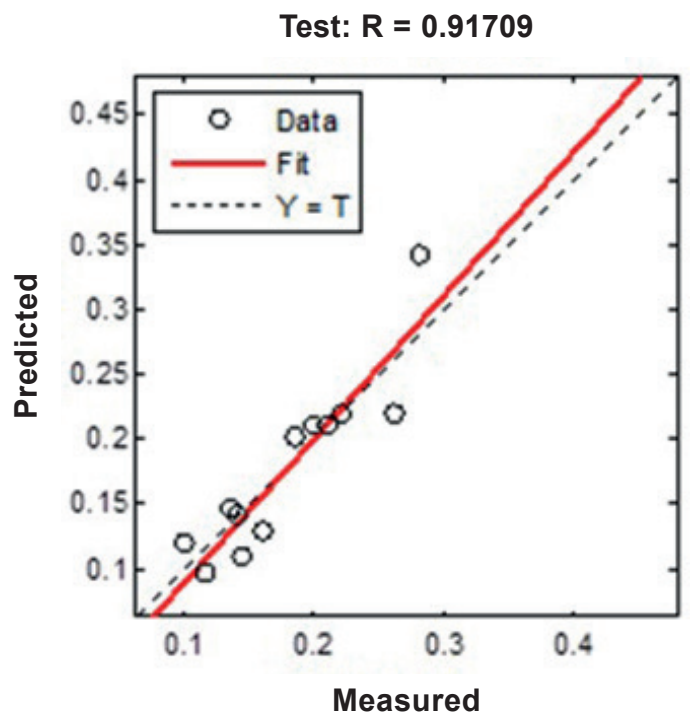

Fig. 11. Regression plot for testing data

testing data is shown in Fig. 11. The estimated values of tool wear are highly correlated with the measured data [24]. The testing data regression value is found to be 0.91709 .

6.2. Validation of ANN-based estimation. The ANN is cross-validated based on the test data given in Table 4 . The estimated values of tool wear from ANN are compared with the experimental value. The comparison plot is shown in Fig. 12.

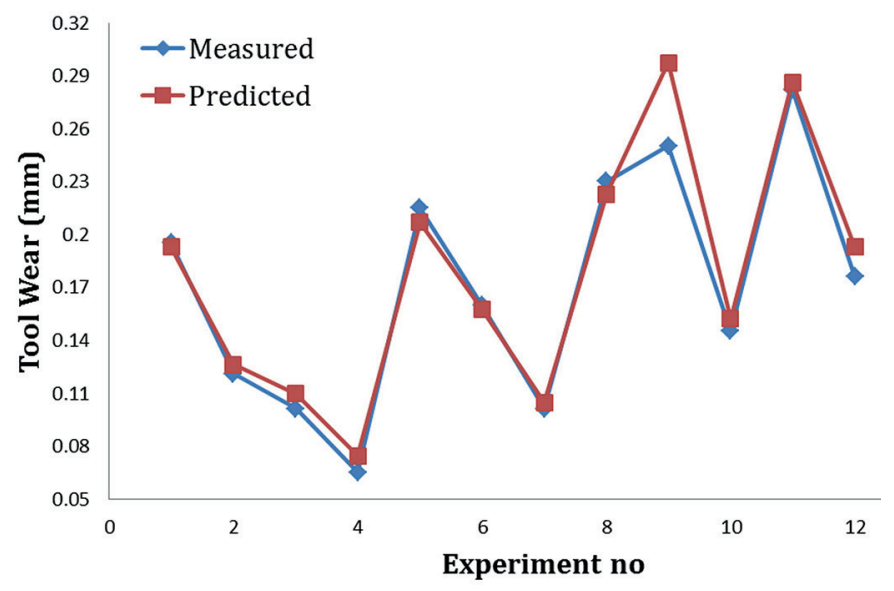

Fig. 12. Measured tool wear and estimated tool wear for cross-validation data

It can be seen that the ANN values closely match the measured values. It is evident from the table for cross-validation data that the error is as low as $6.25 \%$.

The error $(\varepsilon)$ is given by the relation:

$$
\% \operatorname{Error}(\varepsilon)=\left(\frac{\text { Wear }_{\text {exp }}-\text { Wear }_{\text {est }}}{\text { Wear }_{\text {exp }}}\right) \times 100
$$

where Wear $\mathrm{exp}_{\text {and }}$ Wear ${ }_{\text {est }}$ are the measured (experimental) and estimated (ANN) values respectively.

Table 4

Measured and predicted values for cross-validation data

\begin{tabular}{|c|c|c|c|c|c|c|c|c|c|c|c|}
\hline \multirow{2}{*}{ Ex. No } & \multirow{2}{*}{$\mathrm{V}(\mathrm{m} / \mathrm{min})$} & \multirow{2}{*}{$\mathrm{F}(\mathrm{mm} / \mathrm{rev})$} & \multirow{2}{*}{$a_{p}(m m)$} & \multirow{2}{*}{$\mathrm{L}(\mathrm{mm})$} & \multirow{2}{*}{$\mathrm{A}_{\mathrm{z}}(\mathrm{g})$} & \multirow{2}{*}{$\mathrm{F}_{\mathrm{a}}(\mathrm{N})$} & \multirow{2}{*}{$\mathrm{F}_{\mathrm{r}}(\mathrm{N})$} & \multirow{2}{*}{$F_{t}(N)$} & \multicolumn{3}{|c|}{ Tool wear $\left(\mathrm{V}_{\mathrm{b}}\right)$} \\
\hline & & & & & & & & & Measured & Estimated & Error\% \\
\hline 1 & 70 & 0.08 & 0.3 & 600 & 0.06323 & 33 & 94.35 & 68 & 0.195 & 0.192771 & 1.14 \\
\hline 2 & 120 & 0.08 & 0.3 & 400 & 0.035 & 18 & 53.8 & 40 & 0.121 & 0.126111 & 4.22 \\
\hline 3 & 170 & 0.08 & 0.3 & 200 & 0.010861 & 10 & 15.33 & 12 & 0.101 & 0.109636 & 8.55 \\
\hline 4 & 70 & 0.1 & 0.3 & 200 & 0.088654 & 58.33 & 108.2 & 103.5 & 0.065 & 0.074228 & 14.20 \\
\hline 5 & 120 & 0.1 & 0.3 & 600 & 0.04 & 101.7 & 176.4 & 114.3 & 0.215 & 0.206638 & 3.89 \\
\hline 6 & 170 & 0.1 & 0.3 & 400 & 0.009603 & 73 & 108.2 & 105 & 0.16 & 0.15758 & 1.51 \\
\hline 7 & 70 & 0.1 & 0.45 & 200 & 0.11344 & 122.5 & 174.4 & 159 & 0.101 & 0.104596 & 3.56 \\
\hline 8 & 120 & 0.1 & 0.45 & 600 & 0.047548 & 129.3 & 308 & 180.5 & 0.23 & 0.22279 & 3.13 \\
\hline 9 & 170 & 0.12 & 0.45 & 600 & 0.037299 & 160.7 & 366 & 201.3 & 0.25 & 0.297326 & 18.93 \\
\hline 10 & 70 & 0.12 & 0.6 & 200 & 0.3246 & 164 & 477.1 & 338 & 0.145 & 0.152012 & 4.84 \\
\hline 11 & 120 & 0.12 & 0.6 & 600 & 0.091019 & 240 & 484.3 & 410 & 0.282 & 0.286256 & 1.51 \\
\hline 12 & 170 & 0.12 & 0.6 & 200 & 0.037299 & 154.8 & 318.5 & 278.2 & 0.176 & 0.192755 & 9.52 \\
\hline & & & & & & & & & & Avg. error & 6.25 \\
\hline
\end{tabular}




\section{Conclusions}

This paper proposes ANN architecture for tool wear estimation of coated carbide tool, which is seen as a substitute for the expensive $\mathrm{CBN}$ tool in hard turning using variation in force and vibration amplitude. The experimentation is carried out based on full factorial design as per design of experiments. The process parameters, measured cutting force data, and vibration data, along with machining length are used as input variables for ANN and tool wear is taken as the output. Experimental data is used for training. The ANN estimator is formulated after training using the LM algorithm.

The effectiveness of the ANN estimator for the testing data is investigated. The average error is found to be below $10 \%$. Hence, the proposed ANN estimator for tool wear of coated carbide tool using multiple sensors is found to be satisfactory in hard turning operations and can be considered for online wear estimation.

\section{REFERENCES}

[1] H. Aouci, M.A. Yallese, K. Chaoui, T. Mabrouki, and J.F. Rigal, "Analysis of surface roughness and cutting force components in hard turning with CBN tool: prediction model and cutting conditions optimization", Measurement 45 (3), 344-353 (2012).

[2] I. Asilturk and H. Akkus, "Determining the effect of cutting parameters on surface roughness in hard turning using the Taguchi method", Measurement 44 (9), 1697-1704 (2011).

[3] R. Suresh, S. Basavarajappa, and G.L. Samuel, "Some studies on hard turning of AISI 4340 steel using multilayer coated carbide tool", Measurement 45 (7), 1872-1884 (2012).

[4] G. Bartarya and S.K. Choudhury, "State of the art in hard turning", International Journal of Machine Tools \& Manufacture 53 (1), 1-14 (2012).

[5] M. Rizal, J.A. Ghania, M.Z. Nuawia, and C.H.C. Harona, "Online tool wear prediction system in the turning process using an adaptive neuro-fuzzy inference system", Applied Soft Computing 13 (4), 1960-1968 (2013).

[6] G.H. Lim, "Tool wear monitoring in machine turning", Journal of Material processing technology 51 (1-4), 25-26 (1995).

[7] L. Dan and J. Mathew, "Tool wear and failure monitoring techniques for turning a review", Int. J. Mach. Tools Manufact, 30 (4), 579-598 (1990).

[8] D.E. Dimla, "Sensor signals for tool-wear monitoring in metal cutting operations - a review of methods", International Journal of Machine Tools \& Manufacture 40 (4), 1073-1098 (2000).

[9] C. Scheffer, H. Kratz, P.S. Heyns, and F. Klock, "Development of a tool wear monitoring system for hard turning", International Journal of Machine Tools \& Manufacture 43 (10), 973-985 (2003).
[10] X. Wang, W. Wang, Y. Huang, N. Nguyen, and K. Krishnakumar, "Design of neural network-based estimator for tool wear modelling in hard turning", J. Intell. Manuf. 19 (4), 383-396 (2008).

[11] M. Chmielewski and K. Pietrzak, "Metal-ceramic functionally graded materials - manufacturing, characterization, application", Bull. Pol. Ac.: Tech. 64 (1), 151-160 (2016).

[12] D. Dinakaran, S. Sampathkumar, and N. Sivashanmugam, "An experimental investigation on monitoring of crater wear in turning using the ultrasonic technique", International Journal of Machine Tools and Manufacture 49 (15), 1234-1237 (2009)

[13] B. Sick, "On-line and indirect tool wear monitoring in turning with artificial neural networks: a review of more than a decade of research", Mechanical Systems and Signal Processing 16 (4), 487-546 (2002).

[14] A. Siddhpura and R. Paurobally, "A review of flank wear prediction methods for tool condition monitoring in a turning process", Int. J. Adv. Manuf. Technol. 65 (1-4), 371-393 (2013).

[15] H. Chelladurai, V.K. Jain, and N.S. Vyas, "Development of a cutting tool condition monitoring system for high speed turning operation by vibration and strain analysis", Int. J. Adv. Manuf. Technol. 37 (5-6), 471-485 (2008).

[16] D.E. Dimla, "The correlation of vibration signal features to cutting tool wear in a metal turning operation", Int. J. Adv. Manuf. Technol. 19 (10), 705-713 (2002).

[17] O.B. Abouellatta and J. Madl, "Surface roughness prediction based on cutting parameters and tool vibrations in turning operation", Journal of Material Processing Technology 11S8 (1-3), 269-277 (2001).

[18] D.E. Dimla and P.M. Lister, "On-line metal cutting tool condition monitoring.: I: Force and vibration analyses", International Journal of Machine Tools and Manufacture, 40 (5), 739-768 (2000).

[19] V.S. Sharma, S.K. Sharma, A.K. Sharma, "Cutting tool wear estimation for turning”, J. Intell. Manuf. 19 (1), 99-108 (2008).

[20] S.H. Bhuiyan, I.A. Choudhury, and M. Dahari, "Monitoring the tool wear, surface roughness and chip formation occurrences using multiple sensors in turning", Journal of Manufacturing Systems 33 (4), 476-487 (2014).

[21] T. Ozel and Y. Karpat, "Predictive modeling of surface roughness and tool wear in hard turning using regression and neural networks", International Journal of Machine Tools and Manufacture 45 (4-5), 467-479 (2005).

[22] D.E. Dimla and P.M. Lister, "On-line metal cutting tool condition monitoring.: II: Tool-state classification using multi-layer perceptron neural networks", International Journal of Machine Tools \& Manufacture 40 (5), 769-78 (2000).

[23] F.J. Alonsoa and D.R. Salgado, "Analysis of the structure of vibration signals for tool wear detection”, Mechanical Systems and Signal Processing 22 (3), 735-748 (2008).

[24] D. Tanikić, V. Marinković, M. Manić, G. Devedžić, and S. Ranđelović, "Application of response surface methodology and fuzzy logic based system for determining metal cutting temperature", Bull. Pol. Ac.: Tech. 64 (2), 435-445, (2016). 